\title{
Mechanism analysis and performance improvement of mechanized ridge forming of whole plastic film mulched double ridges
}

\author{
Fei Dai ${ }^{1,2}$, Xuefeng Song ${ }^{2}$, Wuyun Zhao ${ }^{2 *}$, Ruijie Shi ${ }^{2}$, Fengwei Zhang ${ }^{2}$, Xuekun Zhang ${ }^{2}$ \\ (1.Gansu Provincial Key Laboratory of Aridland Crop Science, Gansu Agricultural University, Lanzhou 730070, China; \\ 2.College of Mechanical and Electrical Engineering, Gansu Agricultural University, Lanzhou 730070, China)
}

\begin{abstract}
In order to achieve high-performance and mechanization construction standard of whole plastic mulched double ridge seedbed, and to meet its forming process and corresponding agronomic requirements of the mechanized double ridge seedbed, the key working parameters such as the speed of rotary blade group, the thickness of upturned sod and the power consumption of rotary blade group under different parameters were analyzed based on related working performance in ridge forming. Also, the test factors and their range of values were finally determined in this study. Discrete element method (DEM) simulation was applied in the numerical simulation of the mechanized ridge forming process of whole plastic mulched double ridges, and the ridge forming effect and digging resistance variation characteristics of different types of shovels were compared. Taking the forward speed of the combined machine, the penetration angle of the arc-shaped shovel and the depth of rotary tillage as independent variables, and the qualified rate of seedbed tillage as the response value, the mathematical model between the test factors and the qualified rate of the seedbed tillage was established, to explore the influence sequence of the factors on the qualified rate of seedbed tillage, and obtained the following optimal working parameters of the ridge forming device: the advancing velocity of the combined machine of $0.50 \mathrm{~m} / \mathrm{s}$, penetration angle of the arc-shaped shovel of $31^{\circ}$, rotary tillage depth of $140 \mathrm{~mm}$, and average qualified rate $95.20 \%$ of seedbed tillage in corresponding simulation verification test Field test showed that the average qualified rate of seedbed tillage in ridge forming device was $93.60 \%$, which was close to that of the simulation results. The actual working condition of the sample machine was basically in line with the simulation process and could relatively precisely reflect the mechanized ridge forming mechanism of whole plastic double ridges. The results showed that the established DEM model and its parameter setting were relatively accurate and reasonable.
\end{abstract}

Keywords: whole plastic film mulched double ridges, mechanized ridge forming, DEM, numerical simulation, parameter optimization

DOI: $10.25165 /$ j.ijabe.20201305.5747

Citation: Dai F, Song X F, Zhao W Y, Shi R J, Zhang F W, Zhang X K. Mechanism analysis and performance improvement of mechanized ridge forming of whole plastic film mulched double ridges. Int J Agric \& Biol Eng, 2020; 13(5): 107-116.

\section{Introduction}

Furrow sowing technology with whole plastic film mulching on double ridges is a breakthrough and innovative technology in dry farming in Northwest China, which serves as an integration of the functions of evaporation suppression, rainfall collecting and ridge and furrow planting ${ }^{[1,2]}$. By applying the principle of runoff generation on double ridges and flow concentration in furrows, it can store natural precipitation and reduce evaporation from farmland to the greatest extent, and transform precipitation into effective soil moisture to the crop root, thus has improved the efficient water use mechanism in the dry-farming region of the Loess Plateau in Northwest China, and significantly improved the comprehensive agriculture productivity in northwest arid areas, marking great significance in ensuring food security and increasing

\section{Received date: 2020-02-21 Accepted date: 2020-06-03}

Biographies: Fei Dai, PhD, Associate Professor, research interest: design of agricultural mechanization equipment, Email: daifei@gsau.edu.cn; Xuefeng Song, MS candidate, research interest: agricultural mechanization engineering, Email: 549349477@qq.com; Ruijie Shi, Master candidate, research interest: agricultural mechanization engineering, Email: 1139230110@qq.com; Fengwei Zhang, PhD, Professor, research interest: agricultural mechanization engineering, Email: zhangfw@gsau.edu.cn; Xuekun Zhang, Master candidate, research interest: agricultural mechanization engineering, Email: 277981375@ qq.com.

*Corresponding author: Wuyun Zhao, $\mathrm{PhD}$, Professor, research interest: farm machine and mechanical reliability. College of Mechanical and Electrical Engineering, Gansu Agricultural University, Lanzhou 730070, China. Tel: +86-451-7632472, Email: zhaowy@gsau.edu.cn. farmers' income ${ }^{[3]}$.

Furrow sowing technology with whole plastic film mulching on double ridges was first proposed for maize planting, requiring finishing mechanized tillage and forming of big and small ridges and furrows of seedbed before mulching and soil covering, to prepare for sowing seeds on the film in the small ridges ${ }^{[4]}$. Therefore, it is necessary to construct high-performance seedbed with film-mulched double ridges to ensure efficient sowing of the mulched seedbed. If the shape of double ridges is irregular, it will result in malfunction of the film mulching and soil covering device and poor fitting between mulching film and ridges. Therefore, the stability and reliability of the mechanized forming of irregular-shaped double ridges are directly related to the implementation of furrow sowing of the whole plastic film on double ridges. Thus, mechanized ridge forming is the key factor influencing the quality of seedbed. It is necessary to analyze the working mechanism of the technology to ensure the high-performance of double ridges on irregular-shaped seedbed ${ }^{[5,6]}$.

In this study, based on the designed crosswise belt type ridge forming and film-mulching combined machine for whole plastic film mulched double ridge tillage ${ }^{[7]}$, the working performance of the machine in big and small ridges was further improved based on numerical simulation and the actual test. Taking related parameters in tillage as the independent variables, the qualified rate of double ridge tillage was measured under different factor combinations through tests, then response surface method was applied to determine the influence of the factors and their 
interaction effect on the qualified rate of tillage and obtain the optimal combination of working parameters of the machine, to achieve the optimal mechanized ridge forming effect of the whole plastic film on double ridges.

\section{Machine structure and working principles}

\subsection{Structure}

The designed crosswise belt type ridge forming and film-mulching combined machine for whole plastic film mulched double ridge tillage is mainly composed of the suspension device, fertilizer distribution system, spraying system, mechanized ridge forming device, ridge and crosswise belt type soil digging and covering device, ridge film-mulching device, drilling-suppressing device and walking ground wheel. The structure of the machine and key parts in double ridge tillage is shown in Figure $1^{[7]}$.

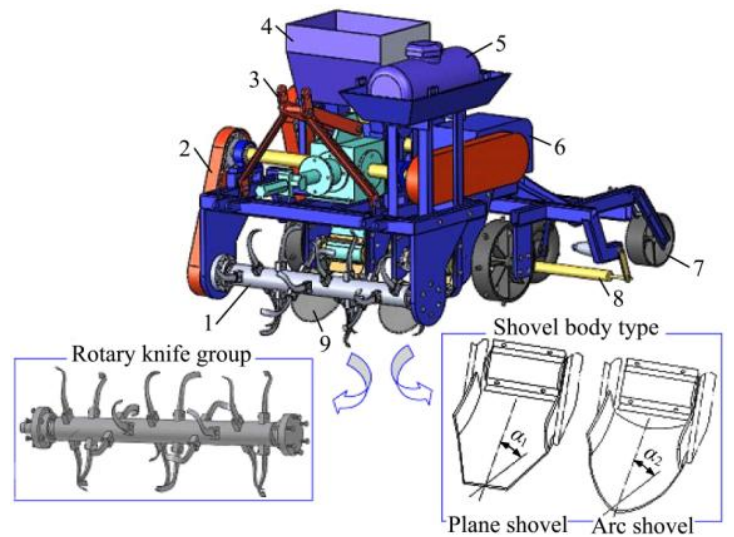

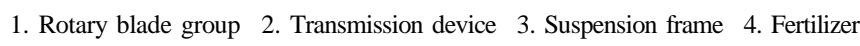
device 5. Spraying device 6. Ridge and crosswise belt type soil digging and covering device 7.Compression device 8.Film-mulching device 9.Digging shovel

Figure 1 Structure of the crosswise belt type whole plastic film ridging and mulching machine on double ridges

A four-wheel tractor is mounted in the rear suspension of the combined machine. The tractor power is input into the gearbox and further transmitted to the rotary blade group to cut the soil, and the digging shovel finishes ditching and ridge forming with the advancing of the rotary blade group. When the rotary blade group cuts and pushes soil to the center, the digging shovel digs ditch, so as to form a double ridge of irregular shape in a mechanized way.

\subsection{Mechanized ridge forming process and agronomic requirements}

As shown in Figure 2, the seedbed of whole plastic-film mulching on double ridges has a big ridge and a small ridge, covering a total width of $1100 \mathrm{~mm}$. The big ridge is 700 in width and $100-150 \mathrm{~mm}$ in height; the small ridge is $400 \mathrm{~mm}$ in width and 150-200 $\mathrm{mm}$ in height. The ridges are all covered by film and seeds are sown in the ditches. The agronomic cultivation mode of whole plastic film mulching on double ridges is shown in Figure $2^{[5,8-9]}$.

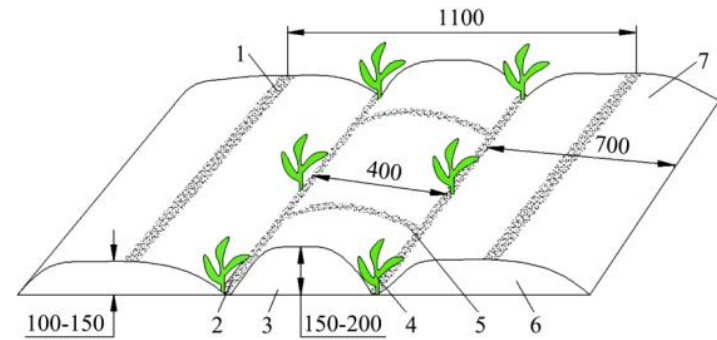

1. Central soil belt on mulching film 2. Soil belt on ridge 3. Small ridge

4. Fertilizer device 5. Crosswise soil belt 6. Big ridge 7. Mulching film

Figure 2 Agronomic cultivation mode of whole plastic film mulching on double ridges

\section{Analysis of key working factors}

\subsection{Ridge forming device}

As shown in Figure 3, the ridge forming device of the combined working machine is mainly composed of a rotary tillage cutter group, a digging shovel and a frame connecting them. The rotary tillage blade is arranged in a double helix on the blade shaft, and the digging shovel of mainly two types (arc-shaped and plane shove) can be replaced in work as required. Meanwhile, the penetration angle of the shovel can be adjusted within the range of $15^{\circ}-45^{\circ}$ according to the mechanized ridge forming effect.

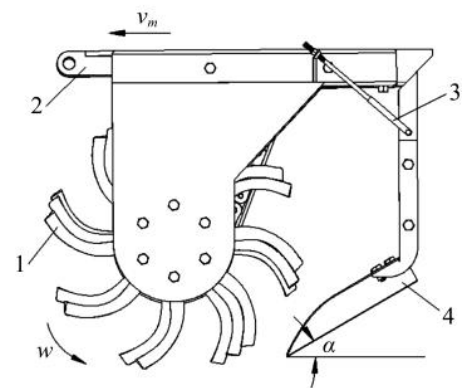

1. Rotary blade group 2. Body frame 3. Penetration angle adjusting device 4. Digging shovel

Note: $v_{\mathrm{m}}$ is the advancing velocity of the combined machine; $w$ is the angular velocity of the rotary blade group; $\alpha$ is the penetration angle of the digging shovel into the soil.

Figure 3 Structure diagram of ridge forming device

When the ridge forming device goes forward with the combined machine, the rotary blade group turns at a high speed, throwing the soil backward and pushing it to the middle. At this time, the shovel completes ditching and realizes the construction of the small ridge and $1 / 2$ big ridge on both sides. Meanwhile, in the ridge forming of the next group, the left side $1 / 2$ big ridge connects with the right side $1 / 2$ big ridge of the last group, and the big ridge is constructed with the connecting and suppression of the central film-mulched soil belt. Therefore, it can be concluded by analyzing the working principle of the ridge forming device that, the advancing velocity of the ridge forming device, the depth of rotary tillage, and the type of shovel and penetration angle have some influence on the quality of the mechanized double ridge forming of the seedbed.

\subsection{Rotary blade group}

As shown in Figure 1, in order to improve the balance of the blade shaft in rotation, 10 blades on the left side of the blade shaft are arranged in dextrorotation, and 10 blades on the right side are arranged in levorotation. In addition to rotating around the axis, the rotary blade also moves at a uniform speed along with the advance of the machine.

In order to let the rotary blade group cut the soil effectively, the movement trajectory of the end point of the rotary blade is a trochoid (rotary speed ratio $\lambda>1$ ), the rotation direction of the rotary blade is clockwise, and the working process of the rotary blade group is shown in Figure $4^{[10]}$.

Taking the rotation center of the rotary blade as the origin point $O$, the movement coordinate system of the rotary blade group was established, and the absolute velocity of the end point of the rotary blade group and the thickness of the upturned sod during positive rotary tillage are:

$$
\left\{\begin{array}{l}
v_{1}=v_{m} \sqrt{1+\lambda^{2}-2 \lambda \sin (w t)} \\
d=\frac{2 \pi v_{m}}{z w} \sin \frac{\lambda \cos (w t)}{\sqrt{\lambda^{2}-2 \lambda \sin (w t)+1}}
\end{array}\right.
$$


where, $v_{1}$ is the absolute speed of the end point of the rotary blade group, $\mathrm{m} / \mathrm{s} ; v_{m}$ is the advancing velocity of the combined machine, $\mathrm{m} / \mathrm{s} ; \lambda$ is the rotary speed ratio; $w$ is the angular velocity of the rotary blade group, $\mathrm{rad} / \mathrm{s} ; z$ is the number of rotary blades in the same plane.

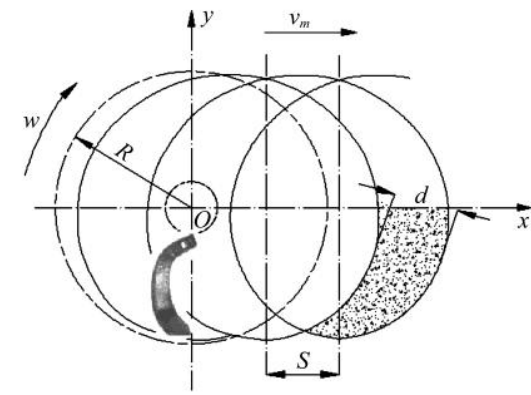

Note: $v_{\mathrm{m}}$ is the advancing velocity of the combined machine; $w$ is the angular velocity of the rotary blade group; $R$ is the turning radius of the rotary blade; $S$ is the bite length; $d$ is the thickness of the upturned sod.

Figure 4 Schematic diagram of working process of rotary blade group

It can be obtained from Equation (1) that, both the absolute speed of the end point of the rotary blade group and the thickness of the upturned sod during positive rotary tillage are related to the advancing velocity of the combined machine $v_{m}$, so the advancing velocity of the combined machine is another key factor affecting the performance of ridge forming. According to preliminary research, the advancing velocity of the combined machine is between $0.5-1.0 \mathrm{~m} / \mathrm{s}$.

In the process of mulching and soil covering, most of the power of the rotary blade group is consumed in entering the soil, soil turning and pushing ${ }^{[11]}$, then the power consumption of the rotary blade group can be estimated approximately as follows ${ }^{[12]}$ :

$$
\left\{\begin{array}{l}
P=0.1 K_{\lambda} v_{m} b d_{1} \\
b=2 b_{1}+b_{2}
\end{array}\right.
$$

where, $P$ is the power consumption of the rotary blade group, $\mathrm{kW}$; $K_{\lambda}$ is the resistance on unit area of rotary tillage, and let $K_{\lambda}=$ $6.3 \mathrm{~N} / \mathrm{cm}^{2[13]} ; b$ is the tillage width of the rotary blade group, $\mathrm{mm}$; $d_{1}$ is rotary tillage depth, and $d_{1}=10-15 \mathrm{~cm} ; b_{1}$ is the width of the $1 / 2$ big ridge, according to cultivation model of the whole plastic film on double ridges (Figure 2), $b_{1}=0.35 \mathrm{~m} ; b_{2}$ is the width of the small ridge, and $b_{2}=0.40 \mathrm{~m}$ according to cultivation model of the whole plastic film on double ridges (Figure 2).

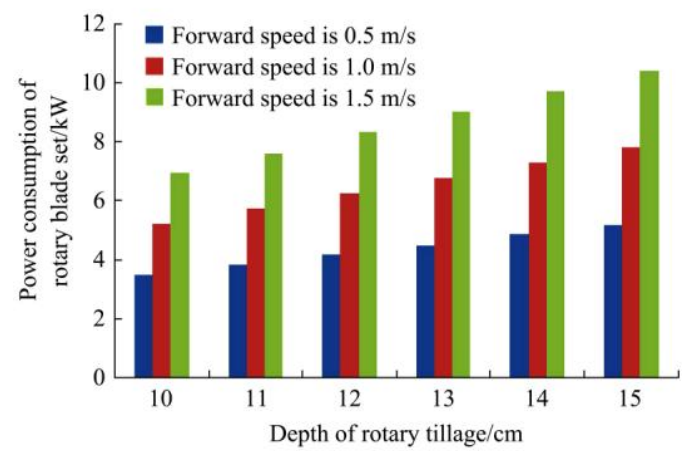

Figure 5 Comparison of power consumption of rotary blade group under different tillage depths and working speeds

When the advancing velocity of the combined machine was $0.5 \mathrm{~m} / \mathrm{s}, 0.75 \mathrm{~m} / \mathrm{s}, 1.0 \mathrm{~m} / \mathrm{s}$, and the rotary tillage depth was $10 \mathrm{~cm}$, $11 \mathrm{~cm}, 12 \mathrm{~cm}, 13 \mathrm{~cm}, 14 \mathrm{~cm}$ and $15 \mathrm{~cm}$, then the power consumption of the rotary blade group in ridge forming was calculated based on Equation (2), and results are shown in Figure 5.
It is shown by comparing the power consumption of rotary blade group under different tillage depths and working speeds that, tilling depth of the rotary blade group had an influence on power output, working performance and construction cost of the seedbed to some extent, and it is one of the key factors affecting the working performance of the ridge forming device.

\section{Simulation test of the mechanized ridge forming of whole plastic film mulching on double ridges}

\subsection{Numerical simulation of mechanized ridge forming process}

In order to further analyze the dynamic characteristics of the ridge forming and ditching by rotary tillage of the ridge forming device, Discrete Element Method (DEM) was adopted for numerical simulation of the working process of the ridge forming device. For convenience in calculation and analysis on the model, also refer to existing research, spherical particles with a diameter of $3 \mathrm{~mm}$ were adopted as soil particles in the modeling, Hertz-Mindlin (no-slip) was adopted for soil particle-soil particle, soil-particlerotary blade group models, and contact model of the digging shovel According to references [5,14-17], the simulation model was set, the parameters in the simulation test are shown in Table 1.

\section{Table 1 Parameters of materials and contact}

\begin{tabular}{|c|c|c|}
\hline Items & Parameters & Numerical values \\
\hline \multirow{3}{*}{ Soil particles } & Poisson's ratio & 0.4 \\
\hline & Shear modulus/Pa & $1.0 \times 10^{6}$ \\
\hline & Density $/ \mathrm{kg} \cdot \mathrm{m}^{-3}$ & 1364 \\
\hline \multirow{3}{*}{$\begin{array}{l}\text { Rotary blade group, } \\
\text { digging shovel }\end{array}$} & Poisson's ratio & 0.28 \\
\hline & Shear modulus/Pa & $3.5 \times 10^{10}$ \\
\hline & Density $/ \mathrm{kg} \cdot \mathrm{m}^{-3}$ & 7850 \\
\hline \multirow{3}{*}{ Soil particle-soil particle } & Recovery coefficient & 0.2 \\
\hline & Static friction coefficient & 0.4 \\
\hline & Dynamic friction coefficient & 0.3 \\
\hline \multirow{3}{*}{$\begin{array}{c}\text { Particle-rotary blade group, } \\
\text { digging shovel }\end{array}$} & Recovery coefficient & 0.3 \\
\hline & Static friction coefficient & 0.4 \\
\hline & Dynamic friction coefficient & 0.1 \\
\hline
\end{tabular}

In order to reduce the running time and storage space of the software, a virtual soil bin (2600 mm (length) $\times 1400 \mathrm{~mm}$ (width) $\times$ $600 \mathrm{~mm}$ (height)) with discrete element mulched film was established for ridge forming. The software Solidworks was used to create the geometric simulation model of the ridge forming device and import it into the EDEM software. The numerical simulation process of mechanized ridge forming is shown in Figure 6 , the simulation time step is $1.23 \times 10^{-5} \mathrm{~s}$, and the total simulation time is $2.40 \mathrm{~s}^{[18,19]}$.

As shown in Figures 6a-6i, when the advancing velocity of the combined machine is $0.75 \mathrm{~m} / \mathrm{s}$, the penetration angle of the arc-shaped shovel is $30^{\circ}$, the rotary tillage depth is $12 \mathrm{~cm}$, and the time $t=0.21-2.40 \mathrm{~s}$, the mechanized ridge forming process of whole plastic film mulching on double ridges was numerically simulated. The observation of the interaction of the rotary blade group, digging shovel and seedbed soil should be started after stable contact was achieved between rotary blade group and soil, therefore, from $t=0.21 \mathrm{~s}$, the DEM numerical simulation approached the working status of mechanized ridge forming, as shown in Figure 6a. When $t=0.36-0.63 \mathrm{~s}$, the arc-shaped shovel followed the rotary blade group to dig the soil and turn it over to form ridges and furrow; when $t=0.86 \mathrm{~s}$, the arc-shaped shovel fully entered the soil and dug up the soil particles, which were mixed 
with the high-speed soil particles after cutting and throwing by the rotary tiller group, resulting in a relatively complicated flow field (Figure 6d); from $t=1.16-2.16 \mathrm{~s}$ (Figures 6d-6g), the boundary between the particle flow field of soil by high-speed rotary cutting and that by digging shovel became clear gradually, and the small ridge in the middle and two $1 / 2$ big ridges on both sides were formed. Also, the positions of soil particle flow by the rotary

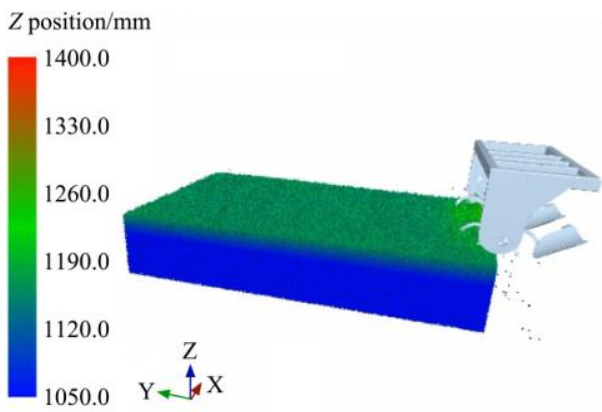

a. $0.21 \mathrm{~s}$

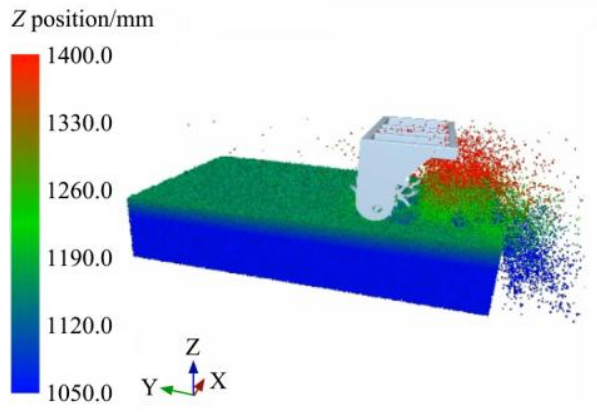

d. $0.86 \mathrm{~s}$

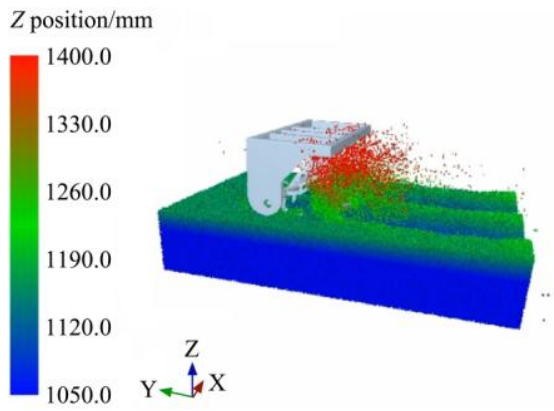

g. $1.66 \mathrm{~s}$

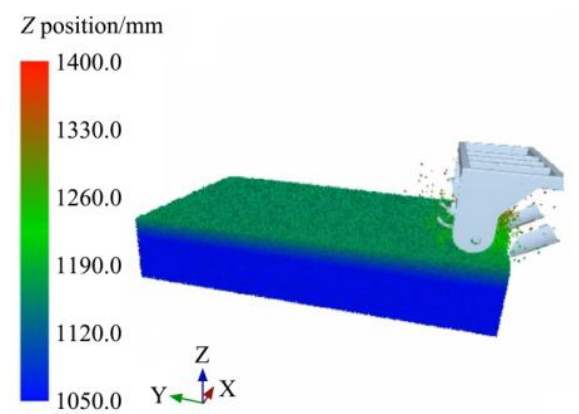

b. $0.36 \mathrm{~s}$

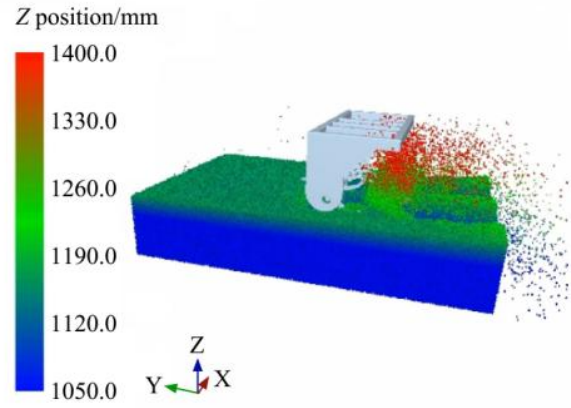

e. $1.16 \mathrm{~s}$

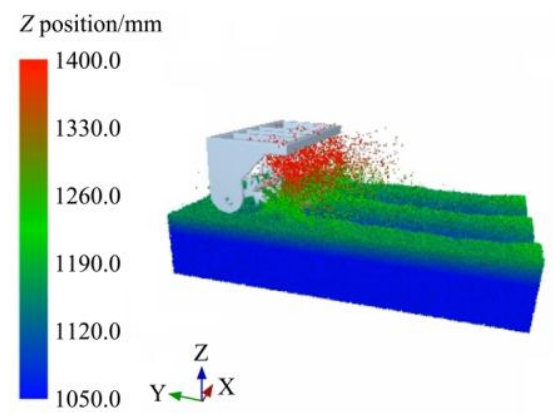

h. $2.16 \mathrm{~s}$

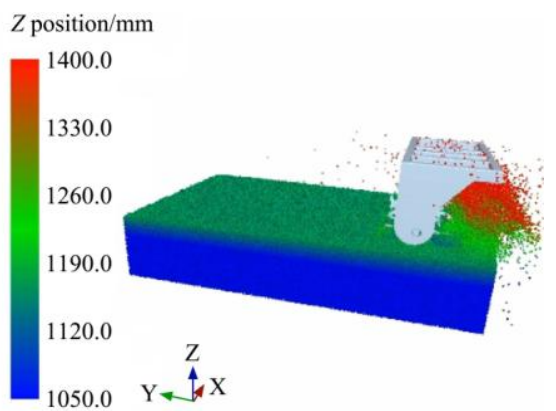

c. $0.63 \mathrm{~s}$

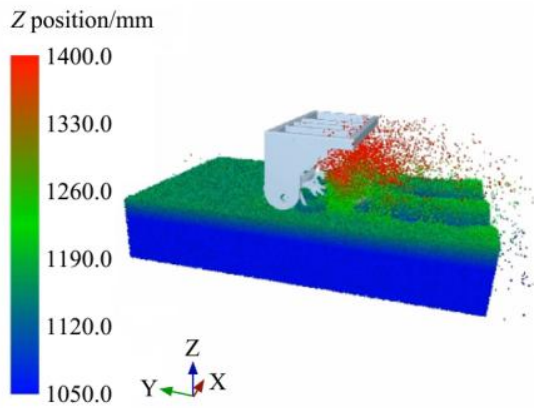

f. $1.36 \mathrm{~s}$

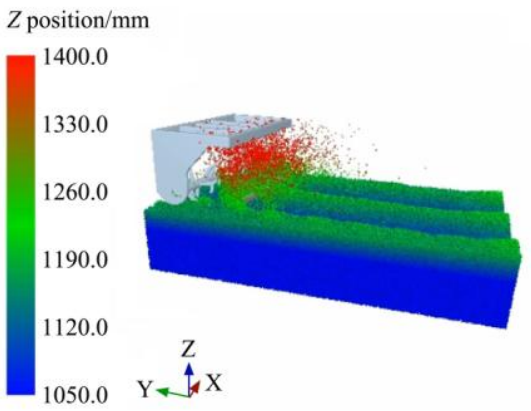

i. $2.40 \mathrm{~s}$

Figure 6 Numerical simulation of the mechanized ridge forming of whole plastic film mulching on double ridges

\subsection{Comparison of the effect of two types of shovels}

Digging shovel is the key component and connecting part in ridge forming and ditching and for the soil digging device. During the operation, it is necessary to make sure that the curve of the formed ridge and furrow is smooth and their shape meets the relevant agronomic requirements, and that the resistance in digging should not be too large.

Two types of shovels, arc-shaped and plane shovels were selected (Figures $7 \mathrm{a}$ and $7 \mathrm{~b}$ ), and the penetration angle of both types of shovels were $30^{\circ}$ (ditching shovel is a part of digging soil, so the tilt angle should not be too large, and the preliminary experimental study shows that the tilt angle $\leq 45^{\circ}$ is appropriate), the advancing velocity of the combined machine was $0.75 \mathrm{~m} / \mathrm{s}$, and the depth of rotary tillage was $12 \mathrm{~cm}$, the specific operation process of the ridge forming device and the effect of double ridge tillage are shown in Figure 7. As shown in Figures $7 \mathrm{c}$ and $7 \mathrm{~d}$, with the same working parameters on the ridge forming device, shapes of shovels had a great influence on the parameters of the double ridge seedbed structure of irregular shape. The plane digging shovel aroused great disturbance in seedbed soil, while the formed ridges had little difference in size. Compared with the working effect of the plane digging shovel, the arc-shaped shovel proved a better ridge forming effect. Since the angle of inclination of the small ridge in the middle was high, and the sunken bottom of the furrow was obvious, it was good for the collection of invalid rainfall under $10 \mathrm{~mm}$ and film-mulching.

Meanwhile, it can be seen from the variation curve of digging resistance of both shovels (Figure 8) under different penetration angles $\left(15^{\circ}, 30^{\circ}, 45^{\circ}\right)$ that, under the same working conditions, the digging resistance of the arc-shaped shovel is slightly higher than that of the plane shovel, mainly because the arc-shape can improve the soil fluidity, also can increase the angle between the shovel bottom plate and the side plate, so as to avoid soil accumulation, and ensure the double effect of ridging and ditching quality. It can be found through the comparison of curves in Figures $8 \mathrm{a}$ and $8 \mathrm{~b}$ that, the digging resistance of the plane shovel was not very sensitive to the variation of penetration angles, which had a more significant influence on the digging resistance of the arc-shaped 
shovel. Therefore, in combination with the characteristics of forming effect and digging resistance of two types of shovels, the arc-shaped shovel is more suitable for double ridge forming of

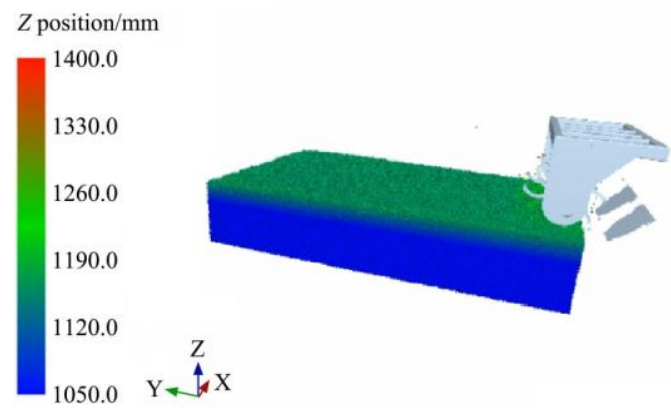

a. Ridge forming model by plane shovel

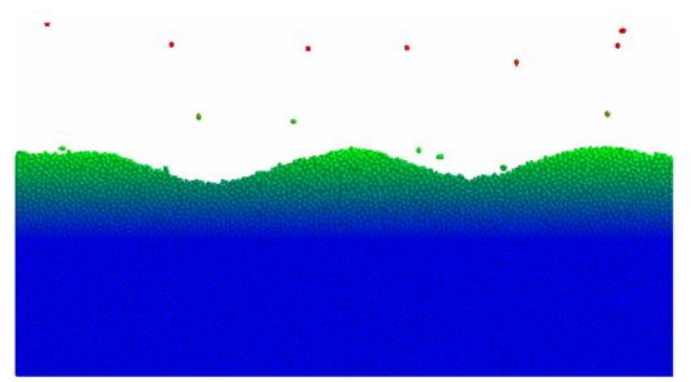

c. Ridge forming effect by plane shovel by arc-shaped shovel whole plastic film mulching, but the penetration angle still needs to be further optimized by test ${ }^{[20,21]}$.

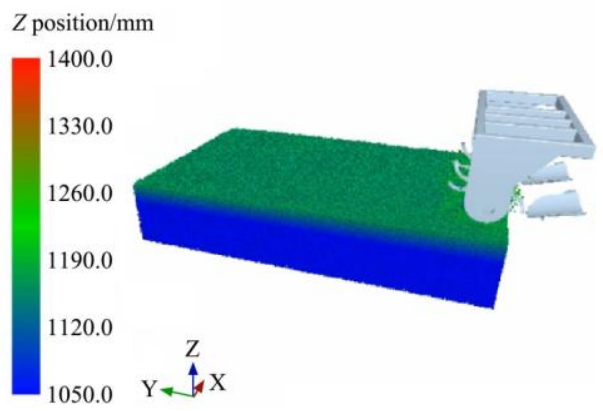

b. Ridge forming model by arc-shaped shovel

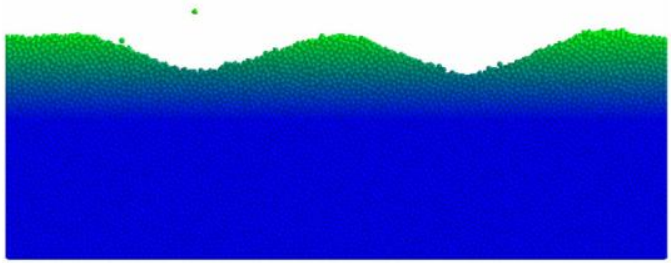

d. Ridge forming effect by arc-shaped shovel

Figure 7 Models of ridge forming device with different types of shovels

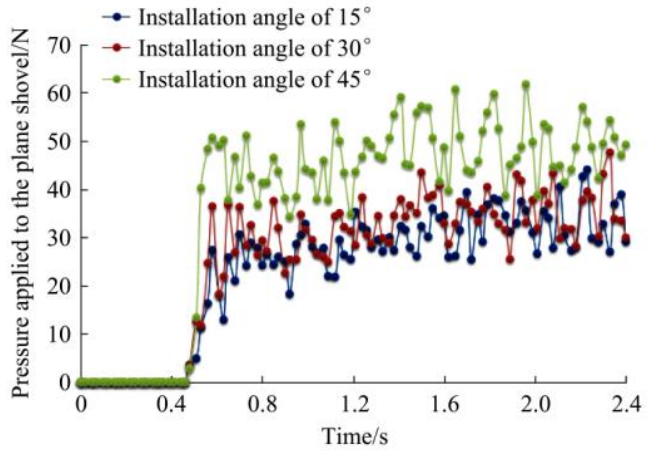

a. Variation of digging resistance under different penetration angle of the plane shovel

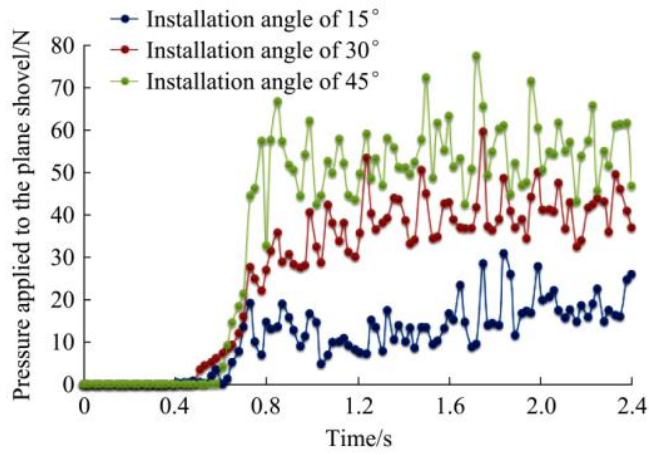

b. Variation of digging resistance under different penetration angle of the arc-shaped shovel

Figure 8 Variation curve of digging resistance under different penetration angle of the two types of shovel

\section{Parameter optimization of ridge forming by arc-shaped shovel}

\subsection{Test design and method}

According to the standard of NY/T 987-2006 of working quality of the plastic film mulching planter and tillage requirement for seedbed of whole plastic-film mulching on double ridges (the total width of ridges is $1100 \mathrm{~mm}$, of which the width of the big ridge is $700 \mathrm{~mm}$ and the height is $100-150 \mathrm{~mm}$; the width of the small ridge is $400 \mathrm{~mm}$ and the height is $150-200 \mathrm{~mm}$, which can be recognized as qualified for the cultivation of double ridges of irregular shape). The tillage qualified rate of the ridge forming device is taken as the evaluation index for the simulation test on working parameter optimization. Based on the simulation model established in Figure 9, the cross-section of seedbed at different positions was solved at random after each simulation test, and the tillage qualified rate of the seedbed was determined. The formula for determining the qualified rate of seedbed tillage is

$$
Y=\frac{N_{1}}{N} \times 100 \%
$$

where, $Y$ is the seedbed tillage qualified rate, $\% ; N_{1}$ is the test points in seedbed tillage; $N$ is the total test points.

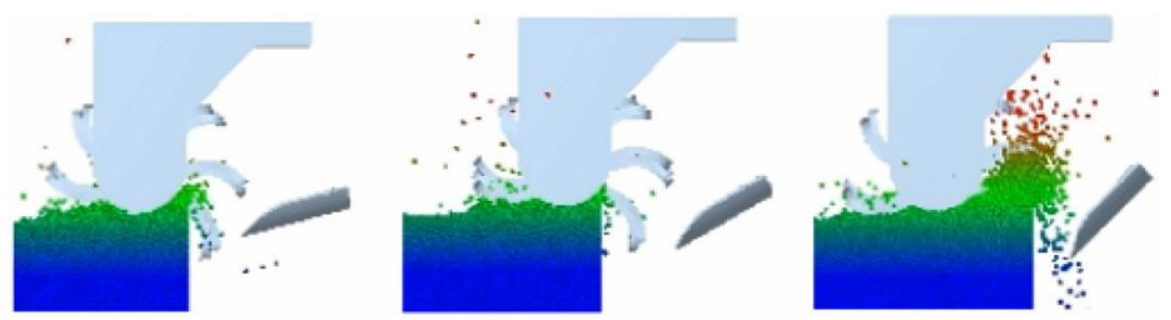

Figure 9 Simulation model of ridge forming by arc-shaped shovel 
Based on the analysis of the working parameters of the arc-shaped shovel in ridge forming, the advancing velocity $x_{1}$ $(0.50-1.00 \mathrm{~m} / \mathrm{s})$, the penetration angle of the arc-shaped shovel $x_{2}$ $\left(15^{\circ}-45^{\circ}\right)$ and the depth of rotary tillage $x_{3}(100-150 \mathrm{~mm})$ were selected as test factors, and the qualified rate of seedbed tillage $Y$ was taken as the evaluation index. Three-factor three-level response surface analysis method was used in the test, and 17 sets of response surface analysis tests (Table 3) were carried out according to the coded levels of each test factor shown in Table 2. Each group of tests was repeated three times, and the average value of the three tests was taken as the test result, then data processing was done by using Design-Expert 8.0.6.1.

Table 2 Coding of factors and levels

\begin{tabular}{cccc}
\hline \multirow{2}{*}{$\begin{array}{c}\text { Coding } \\
\text { table }\end{array}$} & $\begin{array}{c}\text { Factors } \\
\text { Advancing velocity of } \\
\text { the combined machine } \\
x_{1} / \mathrm{m}^{-1} \mathrm{~s}^{-1}\end{array}$ & $\begin{array}{c}\text { Penetration angle of the } \\
\text { arc-shaped shovel } \\
x_{2} /\left(^{\circ}\right)\end{array}$ & $\begin{array}{c}\text { Rotary tillage } \\
\text { depth } \\
x_{3} / \mathrm{mm}\end{array}$ \\
\hline-1 & 0.50 & 15 & 10.0 \\
0 & 0.75 & 30 & 12.5 \\
1 & 1.00 & 45 & 15.0 \\
\hline
\end{tabular}

\subsection{Establishment and test of regression model}

As shown in Table 3, the qualified rate of seedbed tillage could reach $64.5 \%-91.3 \%$, but the performance stability of double ridge tillage and the quality of mechanized ridge forming varied greatly during the test.

Design-Expert 8.0.6.1 was used to analyze test results, and the quadratic regression model of qualified rate $Y$ of seedbed tillage expressed by coding values was obtained.

$$
\begin{aligned}
& Y=85.32-4.40 X_{1}+5.81 X_{2}+0.84 X_{3}-2.47 X_{1}^{2}- \\
& 7.30 X_{2}^{2}-2.15 X_{3}^{2}+3.85 X_{1} X_{2}-1.90 X_{1} X_{3}-1.48 X_{2} X_{3}
\end{aligned}
$$

where, $Y$ is the qualified rate of seedbed tillage, $\% ; X_{1}$ is the coded value of the advancing velocity of the combined machine; $X_{2}$ is the coded value of the penetration angle of the arc-shaped shovel into the soil; $X_{3}$ is the coded value of the rotary tillage depth.

Table 3 Results of response surface analysis

\begin{tabular}{ccccc}
\hline Test No. & $X_{1}$ & $X_{2}$ & $X_{3}$ & $Y / \%$ \\
\hline 1 & -1 & 1 & 0 & 78.9 \\
2 & 1 & -1 & 0 & 64.5 \\
3 & 0 & 0 & 0 & 84.4 \\
4 & -1 & 0 & 1 & 91.3 \\
5 & -1 & 0 & -1 & 82.8 \\
6 & 1 & 0 & -1 & 73.9 \\
7 & 0 & 0 & 0 & 83.6 \\
8 & 1 & 0 & 1 & 74.8 \\
9 & 0 & -1 & -1 & 68.2 \\
10 & 0 & 1 & -1 & 84.9 \\
11 & 0 & -1 & 1 & 69.8 \\
12 & -1 & -1 & 0 & 77.1 \\
13 & 1 & 1 & 0 & 81.7 \\
14 & 0 & 0 & 0 & 87.4 \\
15 & 0 & 0 & 0 & 84.1 \\
16 & 0 & 0 & 0 & 87.1 \\
17 & 0 & 1 & 1 & 80.6 \\
\hline
\end{tabular}

The variance analysis and the significance test of regression coefficients were carried out for the above quadratic regression model. The results are shown in Table 4.

According to the analysis in Table 4 , the $p$-value (0.0045) of the quadratic regression model is less than 0.01 , which indicates that the regression model is very significant; the missing $P$ value $(0.0578)>0.05$, i.e., the misfit is not significant, which indicates that the quadratic regression equation fitted by the model is consistent with the actual situation, and can correctly reflect the relationship between the qualified rate of seedbed tillage $Y$ and factor $X_{1}, X_{2}$ and $X_{3}$. The regression model can be used to predict the results of various experiments in the optimization test. The effects of the first item $X_{1}$ (the advancing velocity of the combined machine), the second item $X_{2}$ (the penetration angle of the arc-shaped shovel) and the second item $X_{2}^{2}$ (the penetration angle of the arc-shaped shovel) on the qualified rate of the seedbed tillage were significant; the interaction item $X_{1} X_{2}$ (the interaction between the advance speed of the combined machine and the angle of the arc shovel) was significant, and the other items were not significant According to the regression coefficient of each factor of the model, the main order of the influence of each factor on the qualified rate of seedbed tillage is $X_{2}, X_{1}, X_{3}$, that is, the penetration angle of the arc-shaped shovel into the soil, the advancing velocity of the combined machine and the depth of rotary tillage.

Table 4 Variance analysis of regression equation

\begin{tabular}{cccccc}
\hline $\begin{array}{c}\text { Source of } \\
\text { variation }\end{array}$ & $\begin{array}{c}\text { Sum of } \\
\text { squares }\end{array}$ & $\begin{array}{c}\text { Degree of } \\
\text { freedom }\end{array}$ & $\begin{array}{c}\text { Mean } \\
\text { square }\end{array}$ & $F$ & $P$ \\
\hline Regression & 802.54 & 9 & 89.17 & 8.85 & $0.0045^{* *}$ \\
$X_{1}$ & 154.88 & 1 & 154.88 & 15.37 & $0.0057^{* *}$ \\
$X_{2}$ & 270.28 & 1 & 270.28 & 26.82 & $0.0013^{*}$ \\
$X_{3}$ & 5.61 & 1 & 5.61 & 0.56 & 0.4798 \\
$X_{1} X_{2}$ & 59.29 & 1 & 59.29 & 5.88 & $0.0457^{*}$ \\
$X_{1} X_{3}$ & 14.44 & 1 & 14.44 & 1.43 & 0.2702 \\
$X_{2} X_{3}$ & 8.70 & 1 & 8.70 & 0.86 & 0.3837 \\
$X_{1}^{2}$ & 25.74 & 1 & 25.74 & 2.55 & 0.1540 \\
$X_{2}^{2}$ & 224.23 & 1 & 224.23 & 22.25 & $0.0022^{*}$ \\
$X_{3}^{2}$ & 19.42 & 1 & 19.42 & 1.93 & 0.2077 \\
Residual error & 70.54 & 7 & 10.08 & & \\
Lack-of-fit & 57.75 & 3 & 19.25 & 6.02 & 0.0578 \\
Error & 12.79 & 4 & 3.20 & & \\
Sum & 873.08 & 16 & & & \\
\hline Note: * significant $(p<0.05)$ and ** extremely significant $(p<0.01)$. &
\end{tabular}

As shown in Figure 10, for the fourth group of tests shown in Table 3, when the advancing velocity of the combined machine was $0.50 \mathrm{~m} / \mathrm{s}$, the penetration angle of the arc-shaped shovel was $30^{\circ}$ and the depth of rotary tillage was $150 \mathrm{~mm}$, the qualified rate of double ridge tillage process of the ridge forming device under different angles of view was $91.3 \%$, as shown in Figure 10e.

As shown in Figure 11, for the 9th group of tests shown in Table 3, when the advancing velocity of the combined machine was $0.50 \mathrm{~m} / \mathrm{s}$, the penetration angle of the arc-shaped shovel was $15^{\circ}$ and the depth of rotary tillage was $100 \mathrm{~mm}$, the qualified rate of double ridge tillage process of the ridge forming device under different angles of view was $68.2 \%$, as shown in Figure 11e.

It was found in the simulation test that there were some differences in the quality effect of the big and small ridges and the furrow after double ridge tillage under different test factor combinations. From the simulation analysis of response surface in the 4th group and the 9th group (Figures 10a-10c and Figures 11a-11c) and cross-sectional size distribution of double ridge tillage (Figures 10d and 11d), it can be concluded that the effect of the penetration angle of the arc-shaped shovel on the qualified rate of seedbed tillage was significant, which is consistent with the variance analysis of the regression equation. 


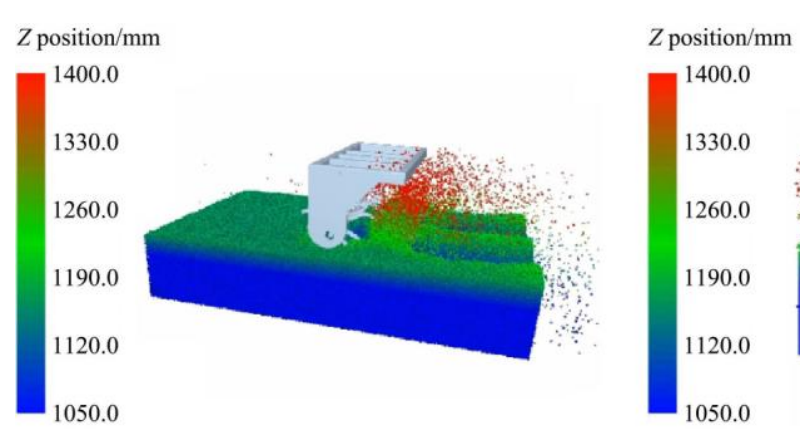

a. Axonometric drawing

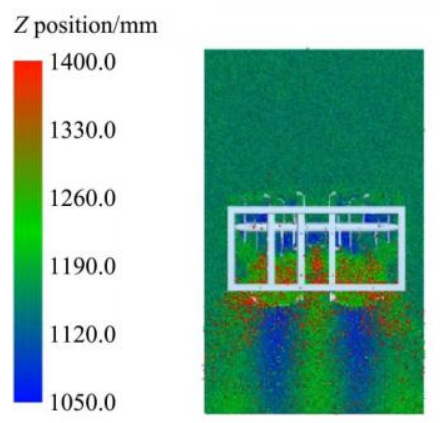

d. Top view

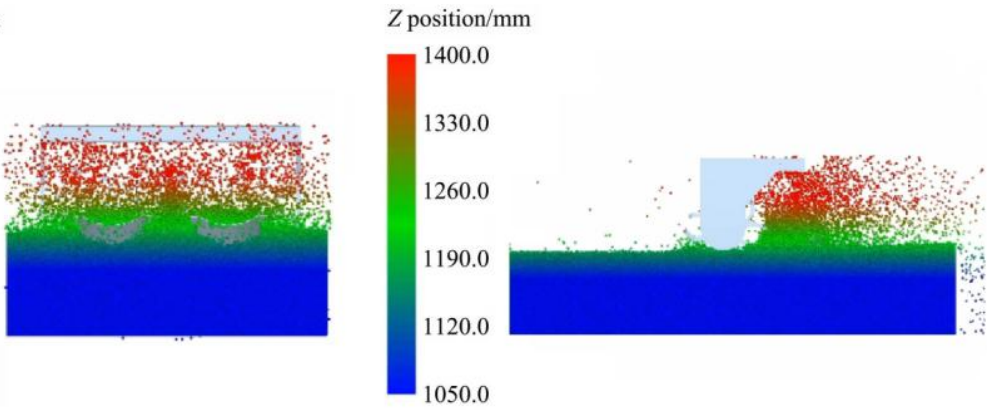

b. Front view c. Left view

Figure 10 The 4th group of response surface simulation analysis tests

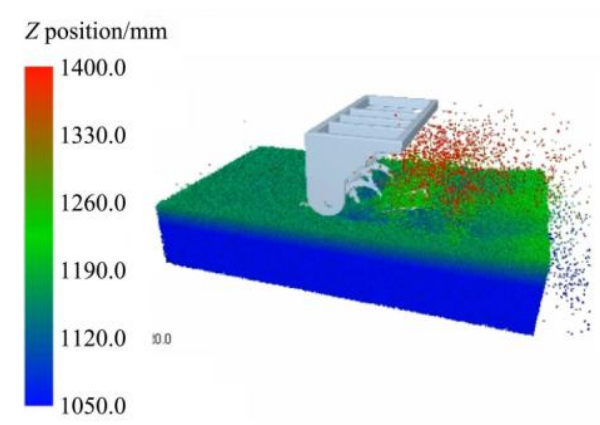

a. Axonometric drawing

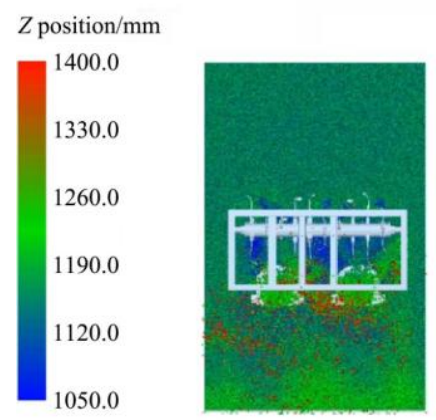

d. Top view
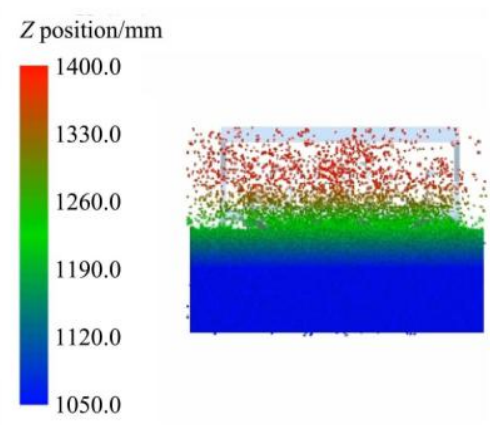

b. Front view

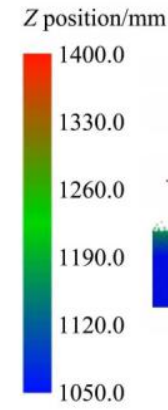

c. Left view

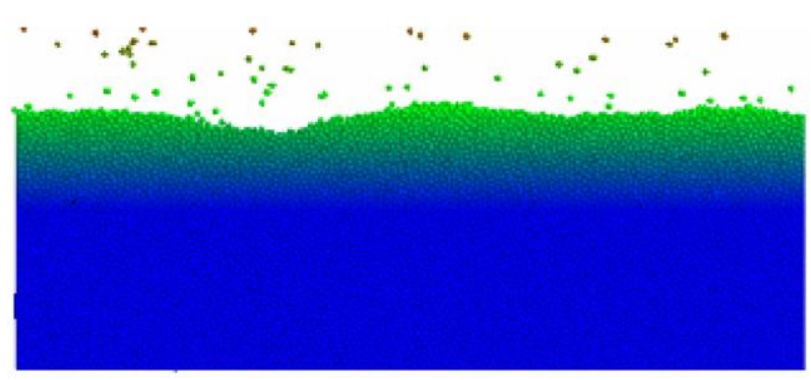

e. Cross-section of double ridge tillage

Figure 11 The 9th group of response surface simulation analysis tests

\subsection{Analysis of interaction items of the model}

According to the quadratic regression model (4), a response surface diagram of the relationship of all test factors can be drawn, and the shape of the response surface can reflect the influence of interaction factors. From the results in Table 4, it can be found that only the interaction between the advancing velocity of the combined machine and the penetration angle of the arc-shaped shovel had a significant effect on the qualified rate of seedbed tillage, while the influence of other interactive factors was not significant. Thus a response surface of two interactive factors was made, as shown in Figure 12.

As can be seen from Figure 12, the qualified rate of seedbed tillage dropped gradually when the penetration angle of the arc-shaped

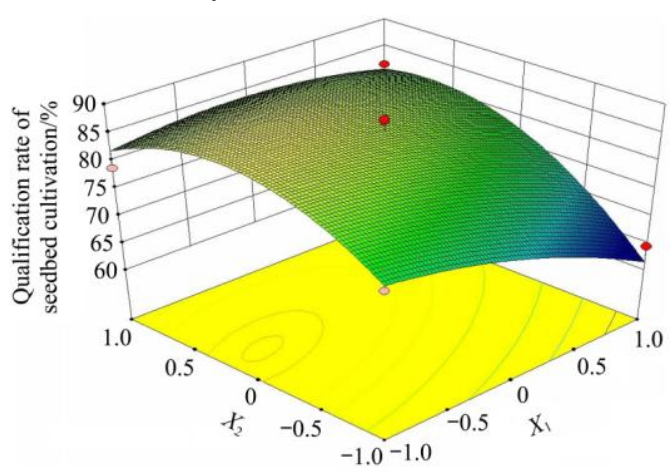

Figure 12 Effects of advancing velocity and penetration angle of arc-shaped shovel on qualified rate of seedbed tillage 
shovel was fixed at a certain level and the advancing velocity of the combined machine increased from $0.50 \mathrm{~m} / \mathrm{s}$ to $1.00 \mathrm{~m} / \mathrm{s}$. The reason is that, with the increase of advancing velocity in ridge forming, the time of soil cutting and pushing as well as digging by the rotary blade group and arc-shaped shovel became shorter, weakening the plasticity of soil, causing falling of soil particles on both sides of the big and small ridges and covering the furrows. As a result, the double ridge tillage of the seedbed could not meet the qualification requirement.

Through the comparative analysis of Figures 13a and 13b, it can be seen that the instantaneous power of the arc-shaped shovel was obviously lower than that at $1.00 \mathrm{~m} / \mathrm{s}$ when the advancing

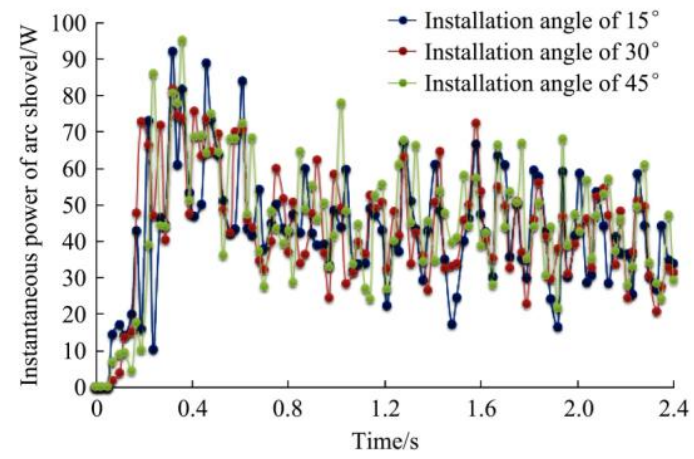

a. Instantaneous power of arc-shaped shovel at advancing velocity of $0.5 \mathrm{~m} / \mathrm{s}$

velocity was $0.50 \mathrm{~m} / \mathrm{s}$, indicating that the advancing velocity of the combined machine had an obvious effect on the energy consumption of seedbed tillage by the ridge forming device. When the power of the combined machine is constant, the advancing velocity is the key factor affecting the double ridge tillage performance of the seedbed, showing consistency with the variance analysis of the regression equation. Meanwhile, under the same advancing velocity, the larger the penetration angle of the arc-shaped shovel was, the higher the instantaneous power of the shovel would be, so it is necessary to find out the optimal working parameters of the ridge forming device.

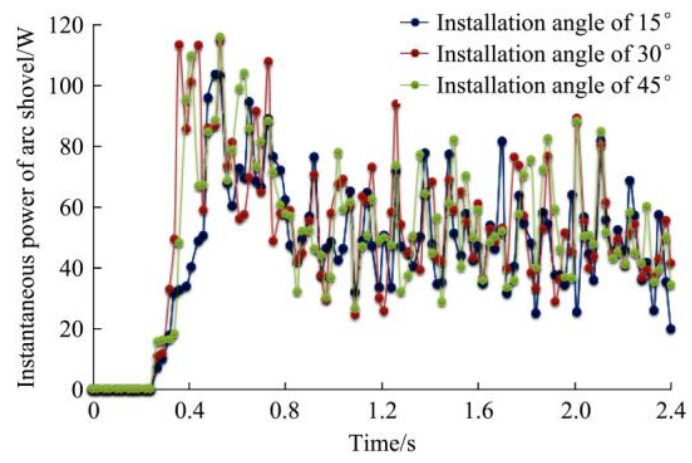

b. Instantaneous power of arc-shaped shovel at advancing velocity of $1 \mathrm{~m} / \mathrm{s}$

-shaped shovel under different advancing speed

5.4 Optimization of working parameters of the ridge forming device

By taking the $100 \%$ qualified rate of seedbed tillage in ridge forming as the target, the Optimization-Numerical module in the software Design-Expert 8.0.6.1 software was used for the optimal solution of the regression equation model, and the optimal working parameters of the ridge forming device were as follows: the advancing velocity of the combined machine was $0.50 \mathrm{~m} / \mathrm{s}$, the penetration angle of the arc-shaped shovel was $31^{\circ}$, and the rotary tillage depth was $140 \mathrm{~mm}$.

In order to verify the reliability of the regression model (4), the optimal working parameters of the ridge forming device were used to simulate the tillage performance of the seedbed (Figure
14). In order to ensure that the simulation model approaches the actual test conditions, the lifting device model that could disturb soil was mounted on the top of the arc-shaped shovel. Test results showed that the qualified rate of seedbed tillage was $95.2 \%$, which was obviously improved before the optimization. The results showed that with the optimized operation parameters, soil cutting and pushing effect in ridge forming could be improved, the depth of furrow excavation could be increased, the disturbance to seedbed soil could be alleviated, the tillage quality of double ridges could be improved, so as to meet the agronomic requirements in furrow sowing on whole plastic film mulching on double ridges. Therefore, the established regression model is reliable.
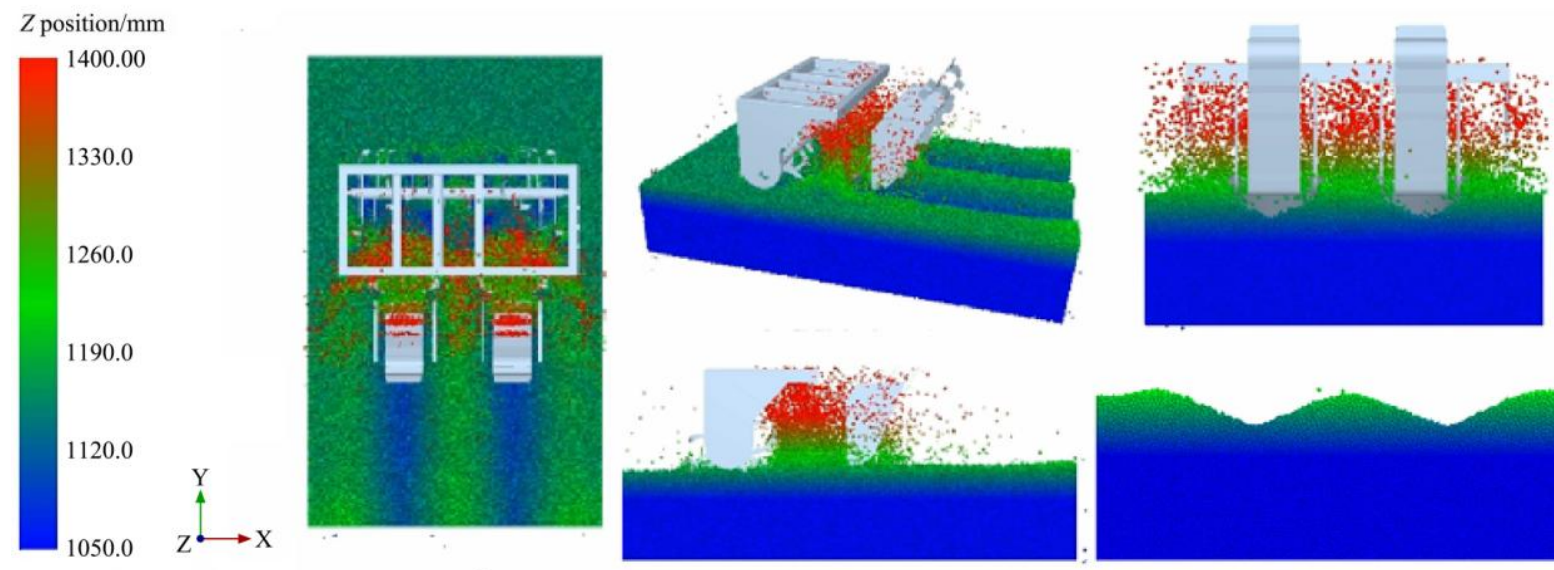

Figure 14 Simulation test on tillage performance of ridge forming device under optimal working parameters

\section{Field verification test}

In order to further verify the tillage performance of the ridge forming device under the optimal working parameters, the test was carried out in the experimental field of Taohe Tractor Manufacturing Co., Ltd. of Lintao County, Dingxi City, Gansu
Province in June 2019 (Figure 15). The soil in the test site was loessal soil with the soil moisture content of $16.86 \%$, the soil bulk density was $1300 \mathrm{~kg} / \mathrm{m}^{3}$, soil compactness $<0.20 \mathrm{MPa}$. The test field was flat, loose with few preceding crops. By referring to the standard NY/T 986-2006 of "Working quality of film mulching machine" and DB62/T 1935-2010 Operation procedure and 
operation quality acceptance of whole plastic double ridge mulching machine", the 15-meter seedbed tillage performance with whole plastic film on double ridges after the operation was tested. The average values of six working areas were taken as the test result, and the qualified rate of seedbed tillage was $93.6 \%$.

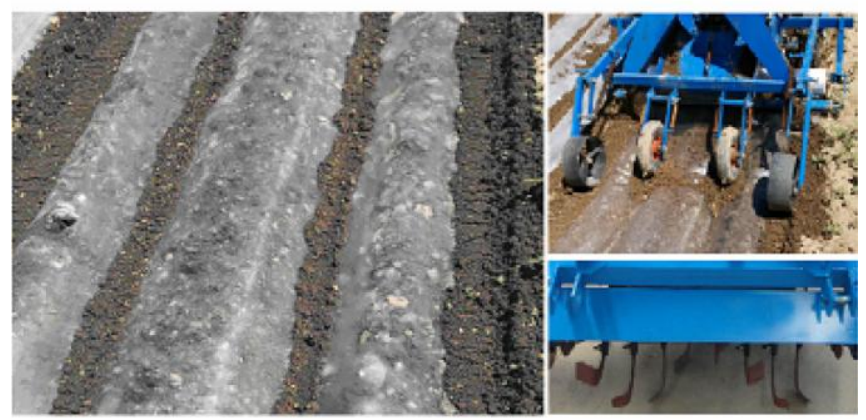

Figure 15 Field performance test

It was found in the test that when the surface of the field is rugged with many soil and stone pieces and the soil moisture content is high, it may easily undermine seedbed tillage quality due to imbalance in cutting of the rotary blade group and the arc-shaped shovel and soil adhesion. The actual working condition of the sample machine was basically the same as the simulation process, which can reflect precisely how the ridge forming device can realize the construction of double ridge seedbed. The result shows that the discrete element simulation model is relatively accurate, and it is feasible to use the discrete element method to simulate and study the ridge forming process through rotary tillage and ditching. At the same time, due to the great difference between the parameters setting of discrete element soil particles and the actual aggregation degree in rotary tillage, and the wide variation of soil moisture content, the actual interaction between the rotary blade group, the arc-shaped shovel and the seedbed soil can not be fully reflected, therefore, it is necessary to further set and optimize the parameters of the model.

\section{Conclusions}

1) According to the structure and working principle of the ridge forming device, the key factors affecting its performance were analyzed and determined. Numerical simulation was carried out on the mechanized ridge forming process on the whole plastic mulched double ridges, in combination with the characteristics of ridge forming effect and digging resistance of two types of shovels, the arc-shaped shovel proved to be more suitable for double ridge forming.

2) Response surface analysis method was applied to establish a quadratic polynomial regression model on the qualified rate of seedbed tillage, the advancing velocity of the combined machine, the penetration angle of the arc-shaped shovel and the depth of rotary tillage. Taking the full qualified rate of seedbed tillage as the target, the optimal working parameters of the ridge forming device were as follows: the advancing velocity of the combined machine was $0.50 \mathrm{~m} / \mathrm{s}$, the penetration angle of the arc-shaped shovel was $31^{\circ}$, and the rotary tillage depth was $140 \mathrm{~mm}$. Under the optimal working parameters, the average qualified rate of seedbed tillage was $95.2 \%$.

3) Field verification test showed that the average qualified rate of seedbed tillage in ridge forming device was $93.6 \%$, which was $1.6 \%$ than that of the simulation results. The actual working condition of the sample machine was basically in line with the simulation process and could relatively precisely reflect the mechanized ridge forming mechanism of whole plastic double ridges. It shows that the established DEM model and its parameter setting were relatively accurate and reasonable.

The research conclusions will effectively promote the entire mechanization level of the production system of whole plastic-film mulching on double ridges, which have great significance to safeguard agricultural productivity in the arid area of Northwest China.

\section{Acknowledgements}

The authors acknowledge that this work was financially supported by the Research Program Sponsored by Gansu Provincial Key Laboratory of Aridland Crop Science, Gansu Agricultural University (No. GSCS-2020-01), National Natural Science Foundation of China (Grant No. 51775115; No. 52065005; No. 51405086), Fuxi Young Talents Fund of Gansu Agricultural University (Gaufx-03Y01), China Agriculture Research System (CARS-14-1-28).

\section{[References]}

[1] Zhou L M, Jin S L, Liu C A, Xiong Y C, Si J T, Li X G, et al Ridge-furrow and plastic-mulching tillage enhances maize-soil interactions: opportunities and challenges in a semiarid agroecosystem. Field Crops Research, 2012; 126: 181-188.

[2] Qin S H, Zhang J L, Dai H L, Wang D, Li D M. Effect of ridge-furrow and plastic-mulching planting patterns on yield formation and water movement of potato in a semi-arid area. Agricultural Water Management, 2014; 131: 87-94.

[3] Dai F, Zhao W Y, Zhang F W, Ma H J, Xin S L, Ma M Y. Research progress analysis of furrow sowing with whole plastic-film mulching on double ridges technology and machine in northwest rainfed area. Transactions of the CSAM, 2019; 50(5): 1-16. (in Chinese)

[4] Dai F, Zhao W Y, Song X F, Zhang F W, Feng F X. Working process analyses of direct insert hill-device with corn whole plastic-film mulching on double ridges based on EDEM. International Agricultural Engineering Journal, 2017; 26(4): 124-131.

[5] Dai F, Guo W J, Song X F, Shi R J, Zhao W Y, Zhang F W. Design and test of crosswise belt type whole plastic-film ridging-mulching corn seeder on double ridges. Int J Agric \& Biol Eng, 2019; 12(4): 88-96.

[6] Li L, Zhang Q, Feng Y C, Nie D, Sun J, Yan M, et al. All-film double-furrow sowing improving water and salt conditions and increasing maize yield in saline soil of cold and arid area. Transactions of the CSAE 2016; 32(5): 96-103. (in Chinese)

[7] Dai F, Zhao W Y, Shi R J, Zhang F W, Ma H J, Ma M Y. Design and experiment of operation machine for filming and girdle covering on double ridges. Transactions of the CSAM, 2019; 50(6): 130-139. (in Chinese)

[8] Gan Y T, Siddique K H, Turner N C, Li X G, Niu J Y, Yang C, et al Chapter Seven-Ridge-furrow mulching systems-an innovative technique for boosting crop productivity in semiarid rain-fed environments. Advances in Agronomy, 2013; 118(1): 429-476.

[9] Dong B D, Liu M Y, Jiang J W, Shi C H, Wang X M, Qiao Y Z, et al Growth, grain yield, and water use efficiency of rain-fed spring hybridmillet (Setaria italica) in plastic-mulched and unmulched fields. Agricultural Water Management, 2014; 143: 93-101.

[10] Zheng K, He J, Li H W, Zhao H B, Hu H N, Liu W Z. Design and experiment of combined tillage implement of reverse-rotary and subsoiling. Transactions of the CSAM, 2017; 48(8): 61-71. (in Chinese)

[11] Lai Q H, Yu Q X, Dong J Y. Dynamic analysis of rotary tiller gearbox based on EDEM, ADAMS and ANSYS. Journal of Intelligent \& Fuzzy Systems, 2019; 36: 1153-1160.

[12] Ji J T, Jia S T, Du X W, He Z T, Liu J J. Design and promotion of $1 \mathrm{GZN}-130 \mathrm{~V} 1$ rotary cultivation ridger. Journal of Chinese Agricultural Mechanization, 2016; 37(1): 1-4, 21. (in Chinese)

[13] Dai F, Zhao W Y, Wang J X, Zhang F W, Feng F X, Zhang F Y. Physical properties of mechanical covering film seedbed with corn whole plastic-film mulching on double ridges. International Agricultural Engineering Journal, 2017; 26(4): 149-156.

[14] Ucgul M, Fielke J M, Saunders C. Three-dimensional discrete element modelling of tillage: determination of a suitable contact model and 
parameters for a cohesionless soil. Biosystems Engineering, 2014; 121(2): 105-117.

[15] Zhao Z, Li Y M, Liang Z W, Gong Z Q. DEM simulation and physical testing of rice seed impact against a grain loss sensor. Biosystems Engineering, 2013; 116: 410-419.

[16] Oldal I, Safranyik F. Extension of silo discharge model based on discrete element method. Journal of Mechanical Science \& Technology, 2015; 29(9): 3789-3796.

[17] Qi L, Chen Y, Sadek M. Simulations of soil flow properties using the discrete element method (DEM). Computers and Electronics in Agriculture, 2019; 157: 254-260.

[18] Wang X Z, Zhang S, Pan H B, Zheng Z Q, Huang Y X, Zhu R X. Effect of soil particle size on soil-subsoiler interactions using the discrete element method simulations. Biosystems Engineering, 2019; 182: 138-150.

[19] Ucgul M, Saundersa C, Li P L, Lee S H. Analyzing the mixing performance of a rotary spader using digital image processing and discrete element modelling (DEM). Computers and Electronics in Agriculture, 2018; 151: 1-10

[20] Barr J B, Ucgul M, Desbiolles J M A, Fielke J M. Simulating the effect of rake angle on narrow opener performance with the discrete element method. Biosystems Engineering, 2018; 171: 1-15.

[21] Ucgul M, Fielke J M, Saunders C. Comparison of the discrete element and finite element methods to model the interaction of soil and tool cutting edge. Biosystems Engineering, 2018; 169: 199-208. 